\title{
INVESTIGANDO O ENSINO DE FÍSICA REALIZADO A UMA ESTUDANTE COM DEFICIÊNCIA VISUAL: REFLEXÕES NECESSÁRIAS NUM ESTUDO DE CASO DE UMA ESCOLA DO OESTE DO PARÁ
}

\author{
Marcos Gervânio de Azevedo Melo, Joanise Soares da Silva, Jucicléia Leitão da Silva \\ Universidade Federal do Oeste do Pará \\ Santarém, Pará \\ E-mail: marcosgervanio@bol.com.br, joanisesoaress@gmail.com, jucicleiasilva10@yahoo.com.br
}

\section{Sani de C. Rutz da Silva, Marcos Cesar Danhoni Neves}

Universidade Tecnológica Federal do Paraná

Ponta Grossa, Pará

E-mail: sanirutz@gmail.com,macedane@yahoo.com

Resumo: Este artigo investiga uma experiência de ensino de Física a uma estudante com deficiência visual de uma escola estadual de Ensino Médio em Alenquer-PA. Realizaram-se entrevistas com o professor de Física da escola, com a estudante e com a professora de acompanhamento do Atendimento Educacional Especializado. Os resultados são discutidos em consonância com estudos da área. Observou-se que a falta de qualificação docente parece ser um dos principais desafios da Educação Especial; em casos como o ensino de Física, que apresenta intenso formalismo matemático, o professor pode ter dificuldades para encontrar alternativas metodológicas que facilitem a inclusão de estudantes com necessidades especiais. A estudante entende que o estudo de Física se voltou para o desenvolvimento de seu raciocínio lógicomatemático e que contribuiu para melhorar o seu entendimento sobre conteúdos conceituais, com destaque para o conteúdo de eletricidade, presente em seu dia a dia.

Palavras-chave: ensino de física, estudante com deficiência visual, qualificação docente.

\section{INVESTIGATING THE TEACHING OF PHYSICS PERFORMED TO A VISUALLY HANDICAPPED STUDENT: REFLECTIONS NEEDED IN A CASE STUDY OF A SCHOOL OF WEST PARÁ}

Abstract: This article investigates an experience of Physics teaching to a visually impaired student from a state High School in Alenquer-PA. Interviews were conducted with the school's Physics teacher, with the student and with the Specialized Educational Attendance accompaniment teacher. The results are discussed in accordance with studies in this area. The lack of educational qualification seems one of the main challenges of the Special Education; in cases such as Physics teaching, which presents intense mathematical formalism, teachers may find it difficult to find methodological alternatives that easen inclusion of students with special needs. The interviewed student understands that studying Physics focuses on developing logical-mathematical reasoning and it contributes to improve your understanding on conceptual contents, highlighting the electricity content, present in her daily life.

Keywords: teaching of physics, visually impaired student, educational qualification.

Recebido em 05/06/2016. Publicado em 30/09/2016. 


\title{
1. INTRODUÇÃO
}

Não é novidade que alguns professores de ciências têm lacunas acentuadas na formação nos cursos de graduação. As instituições formadoras de professores ainda estão caminhando lentamente diante de algumas especificidades e necessidades sociais. A deficiência visual é um dos desafios a ser refletido, na formação docente, nas instituições de nível superior em nosso país.

\begin{abstract}
Teoricamente, esse professor deveria estar preparado para planejar e conduzir atividades de ensino que atendam as especificidades educacionais dos estudantes com e sem deficiência, o que implica dizer que sua prática deve dar conta de atender as múltiplas formas de interação entre os participantes das atividades e os fenômenos estudados (CAMARGO, 2012, p. 15).
\end{abstract}

No entanto, o que se vê na prática é que o professor só experimenta esse contato com estudantes com deficiência visual no momento de sua carreira profissional. Tal situação acaba gerando dúvidas e insegurança por parte do docente que acaba realizando, muita das vezes, o mesmo trabalho para este estudante especial que executa com os outros discentes. A inclusão acaba sendo "mascarada" pela simples presença do estudante na escola como se este fato fosse suficiente para satisfazê-la.

Diante desta problemática, cabe responder a seguinte pergunta: De que maneira os professores de uma escola estadual de ensino médio do município de Alenquer-PA ministraram o conteúdo de Física para atender as necessidades específicas de uma estudante com deficiência visual?

Nesta perspectiva, busca-se investigar de que forma foi trabalhada a disciplina de Física com a estudante com deficiência visual na escola estadual de ensino médio e como isto contribuiu para a sua formação. Especificamente, procura-se verificar a metodologia utilizada pelo docente da disciplina de Física da referida escola para o ensino-aprendizagem da estudante com deficiência visual, além de investigar que contribuição a disciplina de Física, trabalhada na citada escola, proporcionou à estudante em sua própria opinião. Busca-se também analisar o trabalho desenvolvido pela professora de acompanhamento do Atendimento Educacional Especializado AEE com a estudante com deficiência visual na disciplina de Física. 


\section{PROCEDIMENTO METODOLÓGICO}

Os procedimentos executados nesta pesquisa ocorreram na seguinte sequência: Inicialmente, foi realizada uma pesquisa bibliográfica para dar sustentação e fundamentação ao estudo. Posteriormente, realizaram-se entrevistas cuja sequência se deu da seguinte maneira: primeiramente, com o professor de Física da escola estadual de ensino médio, em seguida, com a estudante com deficiência visual e, finalmente, com a professora de acompanhamento do Atendimento Educacional Especializado (AEE).

Após esta etapa, as entrevistas foram trabalhadas dentro de uma análise textual discursiva e os resultados foram discutidos em consonância com os estudos de autores desta área e encontramse apresentadas em três quadros. Esta pesquisa tem um caráter qualitativo com um enfoque para um estudo de caso.

Para tanto, é importante entender e refletir sobre a problemática da deficiência visual para se discutir as possibilidades e dificuldades que esta apresenta no contexto educacional, em especial, na disciplina de Física.

\section{REFLETINDO A DEFICIÊNCIA VISUAL}

A visão é um dos sentidos que nos ajuda a compreender o mundo à nossa volta, ao mesmo tempo em que nos dá significado para os objetos, conceitos e ideias. Os graus da visão abrangem um amplo campo de possibilidades: "desde a cegueira total, até a visão perfeita. A expressão 'deficiência visual' se refere ao espectro que vai da cegueira até a visão subnormal” (GIL, 2000, p. 6).

A delimitação do grupamento de deficientes visuais, cegos e portadores de visão subnormal ou baixa visão, se dá por duas escalas oftalmológicas: acuidade visual (aquilo que se enxerga a determinada distância) e campo visual (a amplitude da área alcançada pela visão) (CONDE, 2009).

Segundo o decreto 5.296 de 02 de dezembro de 2004, cap. II, art. 5o, a deficiência visual é definida como:

[...] cegueira, na qual a acuidade visual é igual ou menor que 0,05 no melhor olho, com a melhor correção óptica: a baixa visão, que significa acuidade visual entre 
0,3 e 0,05 no melhor olho, com a melhor correção óptica; os casos nos quais a somatória da medida do campo visual em ambos os olhos for igual ou menor que 60우 ou a ocorrência simultânea de quaisquer das condições anteriores.

A cegueira significa a alteração grave ou total de uma ou mais funções elementares da visão que afeta de modo irremediável a capacidade de perceber cor, tamanho, distância em um campo mais ou menos abrangente.

Ainda nesse contexto, pode-se dizer que "uma definição simples de visão subnormal é a incapacidade de enxergar com clareza suficiente para contar os dedos da mão a uma distância de 3 metros, à luz do dia" (GIL, 2000, p. 6). Até recentemente, não se levava em conta a existência de resíduos visuais; "a pessoa era tratada como se fosse cega, aprendendo a ler e escrever em braille, a movimentar-se com auxílio de bengala etc." (idem, p. 7).

Nos dias atuais existem profissionais qualificados que trabalham no sentido de aproveitar esses resíduos visuais nas atividades educacionais, na vida cotidiana e no lazer, procurando desenvolver as potencialidades existentes em cada individuo.

As pessoas com deficiência visual na maioria das vezes são consideradas incapazes, ficando escondidas sem terem contato com o mundo que o cerca, deixando de ter uma vida ativa e social. A superproteção da família dificulta o desenvolvimento dessas pessoas a se superarem diante das diversidades encontradas no ambiente escolar e em seu cotidiano como: locomover-se com independência, cuidar-se e vestir-se adequadamente e na adaptação à vida escolar.

A razão pela qual o estudante com deficiência visual não pode ver o que acontece ao seu redor, não deve ser vista como obstáculo no sistema educacional. Através de uma boa orientação em seu processo de ensino aprendizagem, muitas dificuldades e limitações poderiam ser sanadas se os envolvidos como: pais, educadores e gestores educacionais pudessem perceber as potencialidades e habilidades de se relacionar com o mundo e com seus pares. Não perdendo de vista que essa pessoa tem mais semelhanças com os demais do que diferença, sua deficiência não o impossibilita de realizar ações educativas, mas a falta de material apropriado dificulta a sua aprendizagem, fazendo com que fique limitado, deixando de ser incluso para ser apenas ouvinte. Desta forma, faz-se necessário refletirmos esta problemática no ambiente escolar. 


\section{A DEFICIÊNCIA VISUAL NO ESPAÇO ESCOLAR}

Existem inúmeros fatores que influenciam o desenvolvimento educacional de um indivíduo e podemos citar: estrutura institucional, formação docente, falta de apoio familiar dentre outros. Porém, quando nos referimos ao estudante com deficiência visual acrescenta-se a estes fatores o preconceito sofrido no cotidiano social e o tratamento depreciativo que prejudicam a autoafirmação pessoal.

Assim, vale ressaltar que entre os atores pertencentes à educação, ainda existem mitos fortemente enraizados a respeito dos estudantes com deficiência visual, pois é recorrente pensar que tais sujeitos sãos incapazes de exercer quaisquer atividades de forma autônoma, "que devem ser tratados com piedade e com extremo cuidado; que é impossível desenvolver um trabalho em sala de aula posto que não avance em suas aprendizagens" (BRASIL, 2010).

As pessoas cegas têm grandes capacidades como qualquer outro individuo, embora existam restrições, os mesmos possuem habilidades para aprender, conhecer e interagir na sociedade de forma participativa. Neste sentido, o educador deve possibilitar a construção de conhecimentos em sala de aula por meio da orientação e colaboração.

O ensino deve ser planejado e organizado tendo como referência o conhecimento das necessidades individuais do aluno e as características da turma. É preciso conhecer as diferenças dos alunos, questioná-las e valorizá-las (BRASIL, 2010, p. 33).

Nesse sentido, faz-se necessário atentar para algumas estratégias e cuidados que são importantes nas salas de aula inclusivas com estudantes com deficiência visual, pois, como afirma Smith (2008) os docentes devem:

- Colocar a carteira da criança perto do professor, da lousa e da porta da sala de aula.

- Colocar os materiais em locais determinados para que os estudantes possam encontrá-los sem maiores obstáculos.

- Não sair da sala de aula sem avisar à turma;

- Repetir oralmente as informações escritas na lousa; 
- Gravar as aulas de áudio, para que os estudantes as utilizem como apoio em casa;

- Estimulá-los a expressar suas dúvidas, compreensões e necessidades;

- Permitir que utilizem um tempo maior para realizar as atividades;

- Estimulá-los a utilizar recursos e materiais auxiliares;

- Ser bastante específico quando fizer orientações verbais;

- Manter fechadas as portas de armários e as gavetas a fim de evitar acidente;

- Utilizar métodos que favoreçam o aprendizado por meio da audição tipo: músicas e filmes que tratem do assunto da aula;

- Dispor o mobiliário da sala de forma a facilitar a locomoção e o deslocamento do estudante, e evitar acidentes, quando este precisar obter materiais ou informações do professor;

- Utilizar os recursos e materiais adaptados disponíveis: pranchas, presilhas para evitar o deslizamento do papel na carteira, livro falado, equipamento de informática, materiais desportivos como bola de guizo, etc.

- Na avaliação, fazer provas orais com os estudantes que não conseguem enxergar nada ou muito pouco e, com os de baixa visão, fazer uma prova com letras grandes para facilitar a leitura. Com os que já estão alfabetizados em braille, fazer a prova utilizando esse sistema.

Além destas estratégias supracitadas pelo autor, existem recursos ópticos que podem auxiliar o educador no processo de ensino-aprendizagem. Tais auxílios são sistematizados por Sá et al. (2007), destacando-se os quatro apresentados a seguir.

\subsection{Sistema Braille}

Em 1825, Louis Braille, criou um sistema que hoje é conhecido universalmente como sistema braille, no qual as pessoas com deficiência visual podem aprender a ler e a escrever através de códigos, que apresenta a combinação de 63 pontos que representam as letras do alfabeto, os números e outros símbolos gráficos. Vale ressaltar que sua organização é dada em duas colunas verticais com três pontos à direita e três à esquerda de uma organização básica denominada cela braille (SÁ et al., 2007). Este sistema é mostrado na Figura 1. 
Figura 1. Sistema Braille.

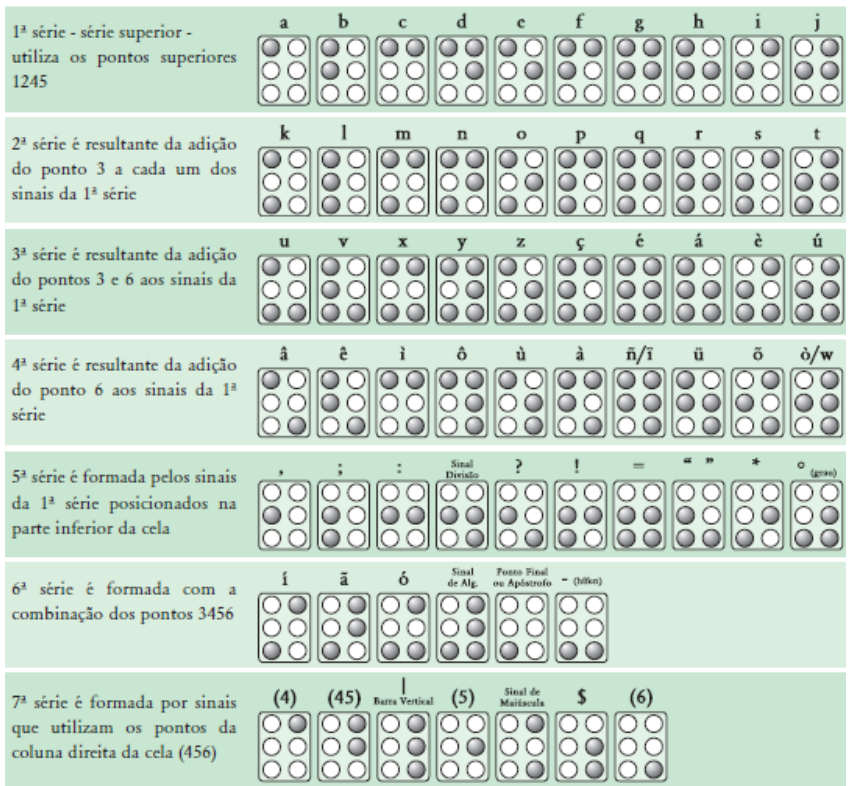

Fonte: Sá et al. (2007, p. 24).

\section{2. $\quad$ Reglete}

É um instrumento feito no formato de uma régua de madeira, metal ou plástico apresentando um sistema de celas braille distribuídas em linhas horizontais sobre uma superfície plana. Precisa da punção, um objeto em madeira ou plástico com características de pera ou anatômico, apresentando ponta metálica, que serve para a perfuração dos pontos na referida cela braille. 0 Reglete pode ser observado na Figura 2.

Figura 2. Reglete.

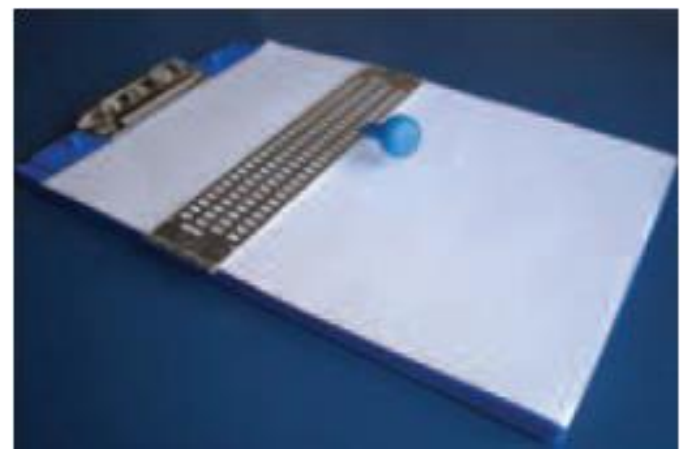

Fonte: Sá et al. (2007, p. 24). 


\subsection{Máquina de escrever}

Configura-se em um sistema de escrita rápido e eficiente e, portanto, um interessante e importante recurso à educação de estudantes com deficiência visual.

Está composto por seis teclas básicas relativas aos pontos da cela braille. A ação simultânea de um conjunto de teclas forma os pontos correspondentes aos sinais e símbolos. A Figura 3 apresenta este importante instrumento à educação especial.

Figura 3. Máquina de escrever.

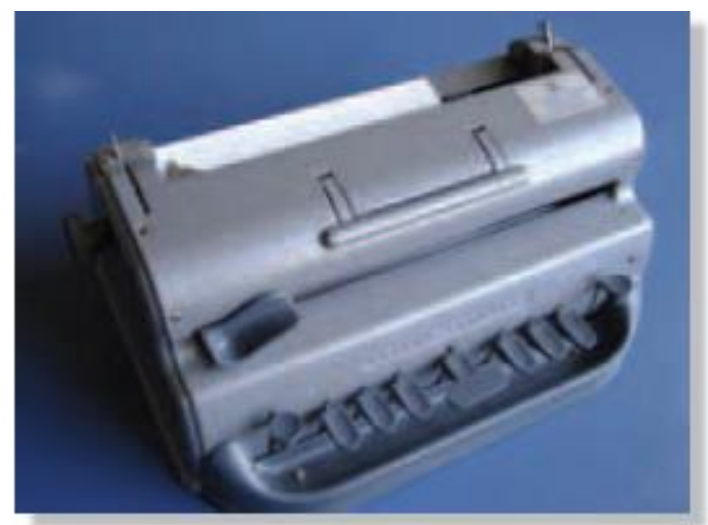

Fonte: Sá et al. (2007, p. 24).

\subsection{Sorobã}

É um equipamento que serve para cálculos e operações matemáticas, um tipo de ábaco apresentando cinco contas em cada eixo. É importante ressaltar que este instrumento é uma adaptação, para a utilização com deficientes visuais, do original Soroban. Contudo, o Sorobã apresenta borrachas compressoras fixando as contas em cada eixo, diferenciando-se, assim, do Soroban original japonês. A Figura 4 esboça uma representação do Sorobã.

Figura 4. Sorobã.

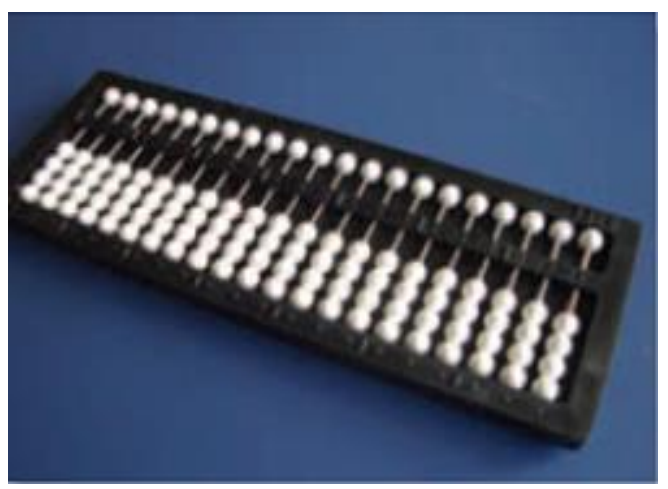


Fonte: Sá et al. (2007, p. 24).

\subsection{Dosvox}

É importante salientar que entre os recursos tecnológicos mais conhecidos e difundidos no Brasil, destaca-se o Dosvox. É um sistema operacional criado pelo Núcleo de Computação Eletrônica da Universidade Federal do Rio de Janeiro. Apresenta um sistema de ferramentas e aplicativos próprios além de ser baseado no uso intensivo de síntese de voz que facilita o acesso dos com deficiência visual no universo computacional. O sistema inevitavelmente potencializa a autonomia do indivíduo e contribui para a motivação das pessoas com deficiência visual nos diversos contextos sociais, em especial, no ambiente de estudo e de trabalho favorecendo a interação com outras pessoas.

Todos esses recursos são necessários ao estudante com deficiência visual, no entanto não se pode esquecer que existem mazelas que são específicas na educação e o ensino de Física tem suas peculiaridades que quando somadas aos problemas vivenciados por este estudante com necessidades educacionais especiais, sinalizam para a conveniência de uma atenção especial do professor desta disciplina.

\section{A DEFICIÊNCIA VISUAL E O ENSINO DE FÍSICA}

A educação especial procura, antes de tudo, corrigir um problema histórico em nosso país, a exclusão de uma parcela da sociedade brasileira que durante anos se viu desprezada pelo poder público. Dessa forma, busca-se assim a inserção de todos na escola em condições de igualdade para que cada um desenvolva suas habilidades e competências desde o jardim de infância até a universidade, proporcionando condições para a sua integração na sociedade. A Lei de Diretrizes Curriculares Nacionais- LDB (LEI no 9394/96) (BRASIL, 1996) estabelece que "todas as crianças têm o direito de frequentar uma escola e de serem alfabetizadas, respeitando as diferenças, os limites e as possibilidades de cada um". Na perspectiva da educação inclusiva é importante lembrar que:

A educação especial, na maioria dos países, segue um padrão semelhante em sua evolução histórica: primeiro, caracteriza-se pela segregação e exclusão, mas depois, com a transformação cultural no que diz respeito às pessoas com necessidades especiais, passa a valorizá-las, reconhecendo suas capacidades e respeitando as suas limitações, principalmente na aprendizagem. Desse modo, 
essas pessoas passam a ser vistas com outros olhos, pois surge o entendimento de que elas precisam ser acompanhadas durante todo o tempo, e isso minimiza a rejeição e o medo (GUEBERT, 2007, p. 69).

Assim, a educação especial aponta para uma valorização do estudante nas suas possibilidades, potencializando a construção de conhecimento e oportunizando o desenvolvimento da autonomia. Medeiros et al. (2007) ressaltam ainda que o aperfeiçoamento da qualidade do ensino regular é um dos objetivos da educação inclusiva, oportunizando, com isso, que todos os estudantes sejam contemplados pelos princípios educacionais, proporcionando, assim, a inclusão dos agentes com deficiência num contexto de naturalidade. Vale lembrar, que os problemas relativos à educação especial parecem se acentuar nas especificidades educacionais, pois para o ensino de Física, Camargo destaca que:

É preciso criar ou adaptar equipamento que emitam sons ou possam ser tocados e manipulados, para que o aluno consiga observar o fenômeno físico a ser estudado. Além disso, o autor destaca que o papel do professor é fundamental, que deve evitar o uso de gestos, figuras e fórmulas que somente podem ser vistos, o professor deve usar materiais de apoio em braille, gráficos em relevo, calculadoras falantes e se necessário, tocar nas mãos dos alunos para apresentarIhes alguma explicação (CAMARGO, 2007, p. 30).

No entanto, é importante destacar que, em alguns casos, a deficiência visual pode até trazer alguma vantagem na compreensão de alguns fenômenos físicos, pois

sabe-se que a mecânica quântica trabalha com fenômenos que ocorrem no nível das dimensões atômicas e das velocidades próximas à da luz. Esses fenômenos não podem ser vistos, já que a visão somente é capaz de observar eventos macroscópicos. [...] Sabe-se também que muitos fenômenos concernentes à luz não são observáveis visualmente. [...] Superar a relação entre conhecer e ver e reconhecer que a visão não pode ser utilizada como pré-requisito para o conhecimento de alguns fenômenos como os de física moderna, pode indicar alternativas ao ensino de física, as quais enfocarão a deficiência visual não como uma limitação ou necessidade educacional especial, mas como perspectiva auxiliadora para a construção do conhecimento de física por parte de todos os alunos (CAMARGO, 2008, p. 25). 
Assim, é necessário que o professor entenda que a pessoa com deficiência visual, embora possua uma compreensão própria do mundo ao seu redor, apresenta capacidades e habilidades que podem ser utilizadas no sentido de potencializar a construção de conhecimento, em especial, do conteúdo de Física, sendo possível compreender os fenômenos dos quais participa no dia a dia, valorizando outros referenciais observacionais como o tátil, o auditivo, o olfativo ou sinestésico.

Portanto, ao apresentar a problemática do estudo e realizar reflexões sobre a deficiência visual no espaço escolar e, em particular, no ensino de Física, faz-se necessário observar os resultados da investigação.

\section{DESCREVENDO RESULTADOS}

As entrevistas realizadas com o professor de Física, com a professora do AEE e com a estudante com deficiência visual proporcionaram um conjunto de informações importantes que estão sistematizadas nos três quadros seguintes. O Quadro 1 apresentará informações relativas à atuação do professor de Física da escola. O Quadro 2 esboçará as ações da professora do Atendimento Educacional Especializado - AEE e o Quadro 3 vislumbrará a trajetória da estudante com deficiência visual.

Quadro 1. Atuação do docente.

\begin{tabular}{|l|l|}
\hline Formação profissional do docente & Licenciatura Plena em Física \\
\hline Tempo de atuação de docência & 16 anos \\
\hline $\begin{array}{l}\text { Estratégias usadas no processo de ensino- } \\
\text { aprendizagem de Física }\end{array}$ & $\begin{array}{l}\text { Experimentos sonoros e térmicos, utilização de } \\
\text { áudio }\end{array}$ \\
\hline $\begin{array}{l}\text { Desafios enfrentados pelo docente no ensino } \\
\text { de Física }\end{array}$ & $\begin{array}{l}\text { Refletir o formalismo matemático no ensino de } \\
\text { Física }\end{array}$ \\
\hline Dificuldades enfrentadas pelo docente & $\begin{array}{l}\text { Não teve formação adequada para trabalhar } \\
\text { esta problemática }\end{array}$ \\
\hline
\end{tabular}

Fonte: dos autores.

E possível observar no Quadro 1 que apesar dos 16 anos de experiência profissional, o professor ressalta ter dificuldades para trabalhar a disciplina Física com a estudante com deficiência visual, pois o mesmo mencionou não possuir preparação adequada para atuar com esta especificidade em sala de aula. O docente ressalta, ainda, que é importante refletir sobre as práticas 
metodológicas direcionadas ao intenso formalismo matemático presente nos assuntos de Física. Pois, é relevante lembrar que

[...] um aluno vidente, quando equaciona e resolve matematicamente um problema físico, pensa sobre o que vai calcular, escreve o cálculo ao longo de uma folha de papel, observa, raciocina e esse processo repete-se ao longo de todo cálculo. O aluno cego, por não conseguir registrar e observar simultaneamente, não executa a relação triádica raciocínio/ registro/ observação, o que o deixa com enormes dificuldades nas atividades de cálculos (CAMARGO, 2012, p. 87).

Com isso, o cálculo no ensino de Física parece ser um obstáculo que merece a atenção tanto de professores da disciplina, quanto de educadores especializados na área de educação especial.

Quadro 2. Atuação da docente de contra turno do AEE.

\begin{tabular}{|l|l|}
\hline Formação profissional & $\begin{array}{l}\text { Licenciatura Plena em Pedagogia } \\
\text { Especialização em Coordenação Pedagógica } \\
\text { Especialização em Atendimento Educacional } \\
\text { Especializado } \\
\text { Cursos de Braille, Libras e Inclusão; Concluindo } \\
\text { Especialização em Libras }\end{array}$ \\
\hline Atividades desenvolvidas na sala do AEE & $\begin{array}{l}\text { Braille } \\
\text { Acessibilidade à locomoção } \\
\text { Tecnologia assistiva }\end{array}$ \\
\hline Estratégias usadas no processo de ensino de Física & $\begin{array}{l}\text { Leitura } \\
\text { Sistema Dosvox } \\
\text { Pesquisa na internet } \\
\text { Auxilio de outros professores }\end{array}$ \\
\hline $\begin{array}{l}\text { Dificuldades enfrentadas para auxiliar a disciplina de } \\
\text { Cílculos } \\
\text { Manuseio do computador no sistema Dosvox } \\
\text { Intercambio entre o professor de Física da série regular e } \\
\text { a professora do AEE }\end{array}$ \\
\hline
\end{tabular}

Fonte: dos autores.

O Quadro 2 apresenta um profissional com intensa bagagem de conhecimento proporcionado por inúmeros cursos de especialização e aperfeiçoamento. No entanto, a docente relata ainda ter dificuldades para trabalhar a disciplina de Física, mencionando o cálculo como um desses obstáculos. Tal fato se intensifica em decorrência de alguns recursos utilizados não colaborarem muito para minimizar este obstáculo, pois 
o braille, em forma tradicional, não contribui para a resolução de cálculos pelos deficientes visuais, pois sua sistemática impede a constituição de referenciais mnemônicos necessários durante os procedimentos de resolução de equações (CAMARGO, 2012, p. 266).

É importante lembrar que tal problemática já fora mencionada pelo professor de Física e encontra-se evidenciada no Quadro 1.

Outro aspecto interessante destacado pela professora do AEE é a dificuldade para realizar encontros com o professor de Física. Isso, certamente, acaba priorizando um trabalho conduzido por planejamentos individuais deixando de proporcionar trocas de conhecimentos entre profissionais de áreas diferentes.

Quadro 3. Trajetória da estudante com deficiência visual.

\begin{tabular}{|l|l|}
\hline Currículo escolar & $\begin{array}{l}\text { 1o ao 5o ano - Escola Vila de Palha (meio rural) } \\
\text { 6o ao 8a série - Escola Polo Nova Esperança Rural (meio rural) } \\
\text { 10 ao 3 ano do Ensino Médio - Escola Estadual Amadeu } \\
\text { Burlamaqui Simões (meio urbano) }\end{array}$ \\
\hline Contato com a disciplina de Física & Somente no Ensino Médio \\
\hline Como ocorriam as aulas & $\begin{array}{l}\text { Conteúdos transcritos no quadro } \\
\text { Apresentação de trabalhos } \\
\text { Testes e provas realizadas oralmente }\end{array}$ \\
\hline Dificuldades enfrentadas & $\begin{array}{l}\text { Não tinha material apropriado } \\
\text { Apostilas e livros não adaptados } \\
\text { Escrevia no quadro } \\
\text { Trabalho em grupo } \\
\text { Conversas paralelas } \\
\text { Atendimento igual aos estudantes normais }\end{array}$ \\
\hline Auxilio da professora do AEE na disciplina de Física & $\begin{array}{l}\text { Pesquisa na internet } \\
\text { Auxilio de outros professores } \\
\text { Ensinava escrever em Braille }\end{array}$ \\
\hline Contribuição da Física & $\begin{array}{l}\text { Desenvolver o raciocínio lógico-matemático } \\
\text { O uso da eletricidade no cotidiano }\end{array}$ \\
\hline
\end{tabular}

Fonte: dos autores.

Analisando o Quadro 3 pode-se perceber que em alguns momentos procurava-se realizar atividades que buscasse favorecer as habilidades da estudante com deficiência visual, pois a simples preocupação com o desenvolvimento de provas orais certamente a coloca em condições de relativa igualdade aos demais discentes. No entanto, várias dificuldades são apontadas pela estudante quando se refere ao ensino de Física que outrora conduziu sua vida educacional. A 
discente ressalta a utilização de livros e apostilas não adaptados, de materiais não apropriados, salientando que as aulas eram escritas no quadro e que tinha um atendimento igual aos demais estudantes.

Como contribuição do contato com a professora do AEE, pode-se destacar a escrita em braille. Porém, a estudante entende que o ensino de Física Ihe proporcionou um trabalho voltado para o desenvolvimento do raciocínio lógico-matemático e contribuiu para melhorar o seu entendimento sobre conteúdos conceituais tendo como destaque a eletricidade presente no dia a dia.

\section{CONSIDERAÇÕES FINAIS}

A falta de qualificação docente certamente é um dos principais problemas que a educação especial pode enfrentar, pois em situações específicas como no ensino de Física, que apresenta um formalismo matemático intenso, o professor, por mais experiente que seja, acaba tendo dificuldades para encontrar alternativas metodológicas para facilitar a inclusão deste discente.

Por isso, se tal obstáculo encontra-se relacionado ao professor de Física, o formalismo matemático acaba sendo um intenso empecilho para a professora do atendimento educacional especializado AEE por esta apresentar formação que indubitavelmente não a favorece, mesmo tendo um interessante currículo voltado à educação especial. O que agrava ainda mais esta situação é a dificuldade de comunicação entre o professor de Física e a professora do AEE, pois o intercâmbio entre esses profissionais certamente favoreceria a discussão de metodologias que minimizassem essa problemática.

A partir desse raciocínio, esse contato entre os professores poderia levá-los a discussões e reflexões que favorecessem soluções para outros entraves mencionados pela estudante com deficiência visual, pois os materiais não adaptados e a escrita no quadro também representam dificuldades que devem ser analisadas.

Finalmente, é interessante refletir que mesmo o professor não apresentando qualificação especifica para trabalhar com a estudante com deficiência visual, não se pode dizer que este não procurou estratégias metodológicas para favorecer a inclusão e isto fica evidente quando o mesmo realiza provas orais e experimentos sonoros, pois estas ações valorizam as diferenças dos estudantes. 


\section{REFERÊNCIAS}

BRASIL. A Educação Especial na perspectiva da inclusão escolar. Brasília: MEC/ Secretária de Educação Especial, 2010.

Congresso Nacional. Lei de diretrizes e bases da educação nacional. Lei no 9394/96. Publicada no diário Oficial da União de 17 de dezembro de 1996. Disponível em: <www.planalto.gov.br/ccivil_03/leis/19394.htm>. Acesso em: mar. 2014.

. Constituição da República Federativa do Brasil de 1988 Disponível em: <www.planalto.gov.br/ccivil_03/constituição/constitui\%C3\%A7ao.htm>. Acesso e março de 2014.

Decreto 5.296, de 02 de dezembro de 2004. Disponível em: <www.planalto.gov.br/ccivil/_ato20042006/2004/Decreto/D5296.htm>. Acesso em: mar. 2014

CAMARGO, Eder Pires de. Ensino de física e deficiência visual. São Paulo: Plêiade, 2008.

. Ensino de Física para alunos cegos ou com baixa visão. Física na Escola, v. 8, n. 1, 2007.

Saberes docentes para inclusão do aluno com deficiência visual em aulas de Física, Editora UNESP, 2012.

CONDE, A. J. M. Define a cegueira e a visão subnormal. Disponível em: <www.ibc.gov.br/?itemid=more>. Acesso em: mar. 2014

GIL, Marta (org.) Deficiência Visual. Brasília: Mec. Secretaria de Educação a Distância, (2000).

MEDEIROS, A.A.; JÚNIOR, M.J.N.; OLIVEIRA, W.C.; OLIVEIRA, N.S.M. Uma estratégia para o ensino de associações de resistores em série/paralelo acessível a alunos com deficiência visual. Em: Atas do XVII Simpósio Nacional de Ensino de Física. São Luís, jan. 2007.

SÁ, Elizabete Dias de; CAMPOS, Izilda Maria de; SILVA, Myriam Beatriz Campolina. Deficiência Visual. São Paulo: MEC/SEESP, 2007.

SMITH, D.D. Introdução à Educação Especial. Ed. Porto Alegre. Artmed, 2008. 